
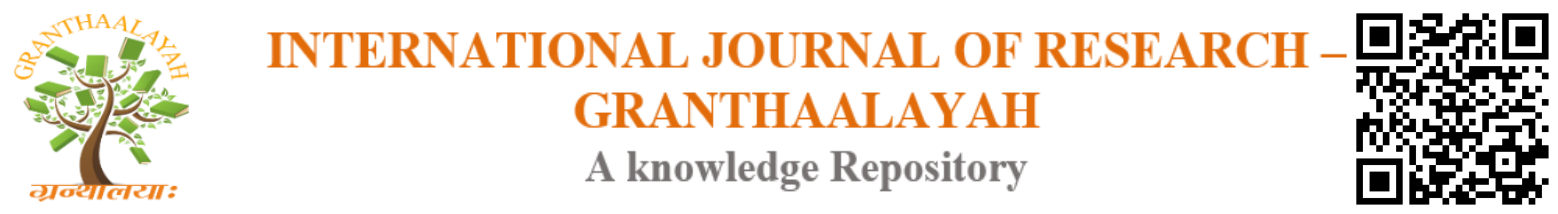

Science

\title{
EFFECT OF PROPOSED PROGRAM OF PATIENT SAFETY ON NURSE'S KNOWLEDGE AND QUALITY OF CARE AT KOSTI AND RABAK TEACHING HOSPITALS-SUDAN
}

\author{
Dr. Hayat Fadllalah Mukhtar ${ }^{1}$, Dr. Mohammed Ibrahim Osman Ahmed ${ }^{2}$ \\ ${ }^{1}$ Associate Professor of Medical Surgical Nursing Karrari University \\ ${ }^{2}$ Assistant Professor of Medical Surgical Nursing Al Amal Complex for Mental Health -Riyadh- \\ Sudia Arabia
}

\begin{abstract}
Background: The profession of Nursing has been at the forefront of patient safety taking special attention to the training and education of its workforce. Internationally, the International Council of Nurses (ICN) has been tackling this issue with force since it established that Patient safety is fundamental to quality health and nursing care

Aim: To study the impact of a design propose program for nurses about patient safety and evaluate the impact of it on nurses knowledge.

Methodology: This was quiz experimental study, one hundred eight nurses were included as all the entire population meeting the inclusion criteria taken as a sample, using census to achieve a desirable level of precision, the data was collected in four phases using a self-administered questionnaire, phase one include an orientation about the training program. Phase two (pretest data), in which the questionnaire was distributed for nurses and each one was allowed sufficient time to fill it. After collection of pretest data the nurses were received the training program, the training was continued for four months. Phase three: A posttest was obtained from the participants at the end of the program, the same self-administrative questionnaire. Follow up phase include the same process in phase three after one, two and three months to make sure of the consistency. The data was analyzed by (SPSS) program with (P. value, mean, standard deviation, T. test and chi squire test).
\end{abstract}

Results: The present study revealed that the nurse's knowledge were improved affected by the proposed training program. The mean of nurse's knowledge regarding maintain patient safety was improved, in pre intervention ( $3.77+/-$ Std 1.24$)$ to be $(4.44+/-$ Std 0.60$)$ in posttest I which get better to $(4.93+/-$ Std 0.283$)$ in posttest II , and it was $(4.13+/-$ Std 0.613 ) in posttest III, there was highly statistically significant association between the nurses knowledge and application of training program $(\mathrm{p}=0.000)$.

Recommendations: Great emphasis should be directed towards the educational aspects on patient safety by providing educational posters, guidelines, pamphlets, manual and modern educational facilities, collaboration should be encourage between institutions and federal ministry of health to formalize a protocol of patient safety.

Keywords: Proposed; Teaching; Driver; Hospitals. 
Cite This Article: Dr. Hayat Fadllalah Mukhtar, and Dr. Mohammed Ibrahim Osman Ahmed. (2019). "EFFECT OF PROPOSED PROGRAM OF PATIENT SAFETY ON NURSE'S KNOWLEDGE AND QUALITY OF CARE AT KOSTI AND RABAK TEACHING HOSPITALS-SUDAN." International Journal of Research - Granthaalayah, 7(2), 10-17. https://doi.org/10.29121/granthaalayah.v7.i2.2019.989.

\section{Introduction}

Patient safety is the foundation of good patient care, the unnerving fact that healthcare can harm us as well as heal us is the reason for suggesting that patient safety is the heart of healthcare quality. Effectiveness, access to care, timeliness and the other dimensions of quality are all important. But when a member of family goes into hospital or receives other healthcare then above all family member want them to be safe. There is something horrifying about being harmed, or indeed causing harm, in an environment of care and trust. Both for patients and staff, safety is the emotional heart of healthcare. It's also believe in terms of understanding, improvement and dayto-day running of health care that safety is a touch's one and guide to the care that is given to the patients; the clinician nurses or the organization that keeps safety to the fore in the midst of the many other often competing priorities achieves something remarkable and provides the care that we would all want to receive ${ }^{(1)}$.

Now a days, patient safety is one of the Nations' most health care challenges, there is increasing number of patients who die in hospitals each year as the result of lapses in patient safety practice. Improving patient safety, remains a health care organizational challenge, compared to other industries with highly reliable processes, health care baseline process reliability is low and patient safety solutions continue to be a high demand ${ }^{(2)}$.Patient Safety has been an issue of paramount importance for the Nursing profession since the early work by Florence Nightingale, which included setting care and hygiene standards in hospitals to combat deadly healthcare associated infections and avoidable complications thus championing the safety of patients. Particularly, in 1854 during the Crimean War Florence Nightingale collected data on mortality rates of soldiers which she divided into three categories: deaths caused by preventable contagious diseases, deaths due to infections of patient's wounds, and deaths from all other. It soon became obvious to Nightingale that soldiers were dying as patients in field hospitals from avoidable complications and infections at a faster rate than those dying on the battlefield. Consequently, she implemented actions to improve standards of care resulting in the death rate falling drastically and planting the seeds of the patient safety movement for the decades to come ${ }^{(3) .}$

The profession of Nursing has been at the forefront of patient safety taking special attention to the training and education of its workforce. Internationally, the International Council of Nurses (ICN) has been tackling this issue with force since it established that Patient safety is fundamental to quality health and nursing care. ICN believes that the enhancement of patient safety involves a wide range of actions in the recruitment, training and retention of health care professionals, performance improvement, environmental safety and risk management, including infection control, safe use of medicines, equipment safety, safe clinical practice, safe environment of care, and accumulating an integrated body of scientific knowledge focused on patient safety and the infrastructure to support its development. ${ }^{(11)}$ 
The study on the state of the art on Patient Safety in Europe including literature on high reliability organizations, medication errors, and hospital acquired infections. This work was subsequently used to inform discussions in the European Commission and Parliament regarding the proposed Council Recommendation on Patient Safety and Healthcare Associated Infections. Finally, the Position Statements describe general requirements for Patient Safety with particular reference to the need for education on Patient Safety. ${ }^{(13)}$ The integration of Patient Safety Core Curriculum guidelines for the development of Patient Safety modules in nursing education systems is welcomed. ${ }^{(4)}$.

Communication is central to human interaction. Without it, people cannot relate to those around them, make their needs and concerns known or make sense of what is happening to them. One of the most basic goals for nursing staff is that their patients and clients and those who care for them. Experience effective communication. (14) Nurses and nursing staff are at the heart of the communication process: they assess, record and report on treatment and care, handle information sensitively and confidentially, deal with complaints effectively, and are conscientious in reporting the things they are concerned about. Information that is accessible, acceptable and accurate, and that meets patients' and clients' needs, shared actively and consistently. nursing Staff communicate effectively with each. ${ }^{(15)}$ other to ensure continuity, safety and quality of health care for all, Documentation, communication during handover, information sharing, managing complaints, and reporting incidents and concerns are the more formal aspects of communication (12).

\section{Justification}

In the past, they have often viewed nurses responsibility in patient safety in narrow aspects of patient care, for example, avoiding medication errors and preventing patient falls. While these dimensions of safety remain important within the nursing purview, the breadth and depth of patient safety improvement are far greater. So, nurses are at the front lines of health care delivery. In fact, they constitute the largest group of health care professionals providing direct care to patients. The most critical contribution of nursing to patient safety, in any setting, is the ability to coordinate and integrate the multiple aspects of quality within the care directly provided by nursing, and across the care delivered by others in the setting. ${ }^{(16)}$

Nurses and other health care professionals are under increased security to provide safe, effective care. Likewise, nursing education programs are faced with increased pressure to be more adapted about practice of patient safety. Moreover, nurses are in a unique position to improve patient safety because of their inherent proximity to patients. This position gives nurses the needed insight to identify problems in healthcare systems and to be part of patient safety solutions. However, to do this, nurses must be supported and encouraged without fear of retribution, as well as have an understanding of how organizational culture change can be accomplished (6)

The fundamental role of the nurse is to provide quality patient care and support for those suffering from health problems, yet these functions have often been disregarded by health care organizations. Nurses have not been treated as professional caregivers even though their presence at the bedside can literally mean life or death for their patients (5). There is no enough research dealing with the patient safety In Sudan just regarding with infection control, with the importability of the maintaining of patient safety worldwide. This study aim to implement 
educational program for nurses about patient safety involves a wide range of actions in the recruitment, training and retention of health care professionals, performance improvement, environmental safety and risk management, including infection control, safe use of medicines, equipment safety, safe clinical practice and safe environment to avoided harm of our patients.

\section{Objectives}

\section{General Objective}

To study the effect of a design propose program for nurses about patient safety and evaluate the effect of it.

\section{Specific Objectives}

1) To identify basic knowledge of nurses about safety communication, patient monitoring, safety medication administration, safety environment and infection control .

2) To design and Implement training program for nurses about patient safety.

3) To assess the effectiveness of the designed program for nurses knowledge regarding patient safety.

\section{Results}

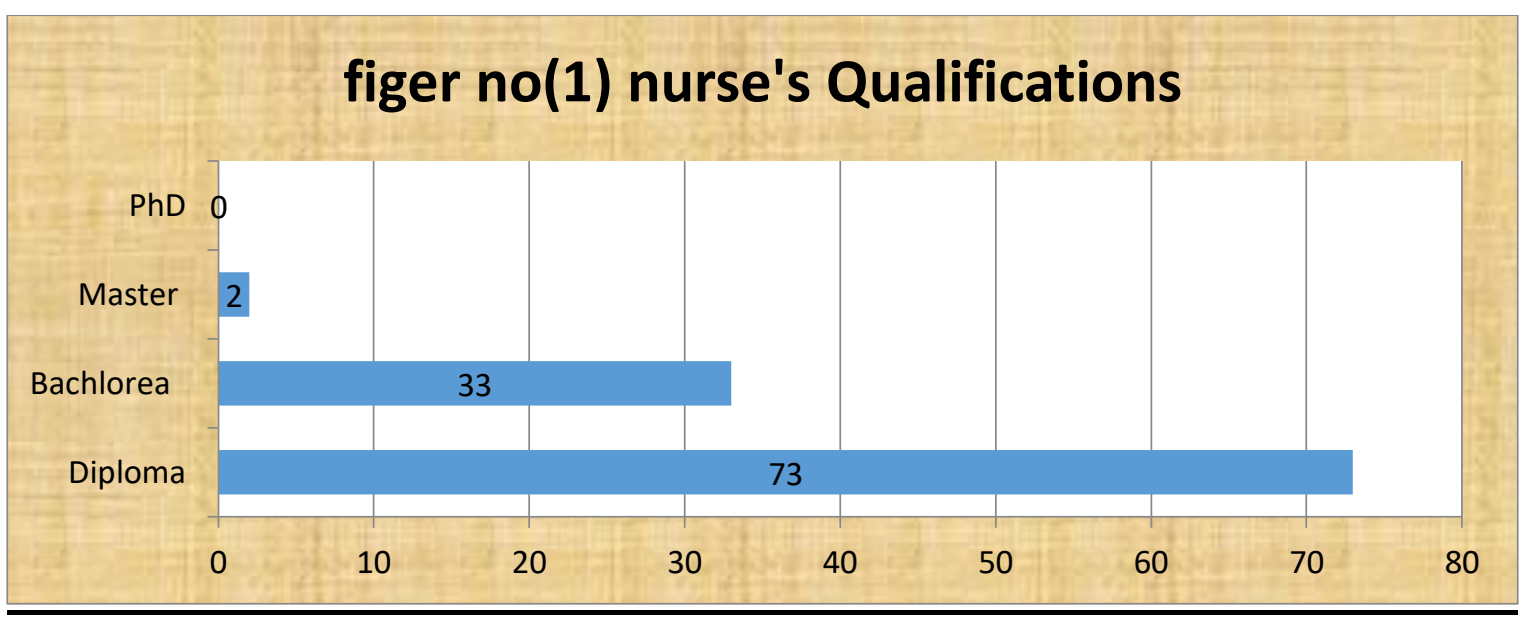

figer no(2) nurse's Years of experience

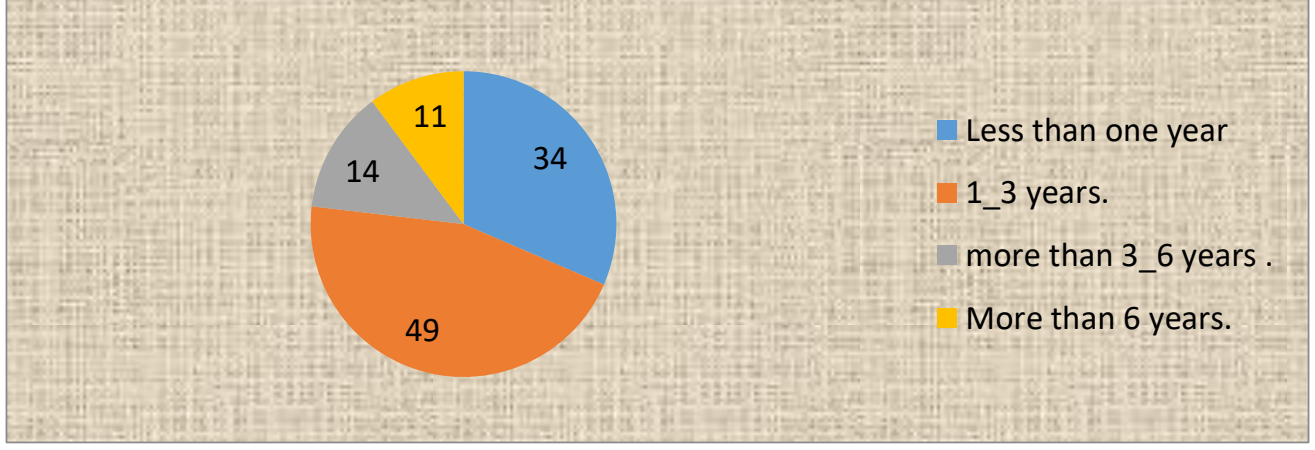




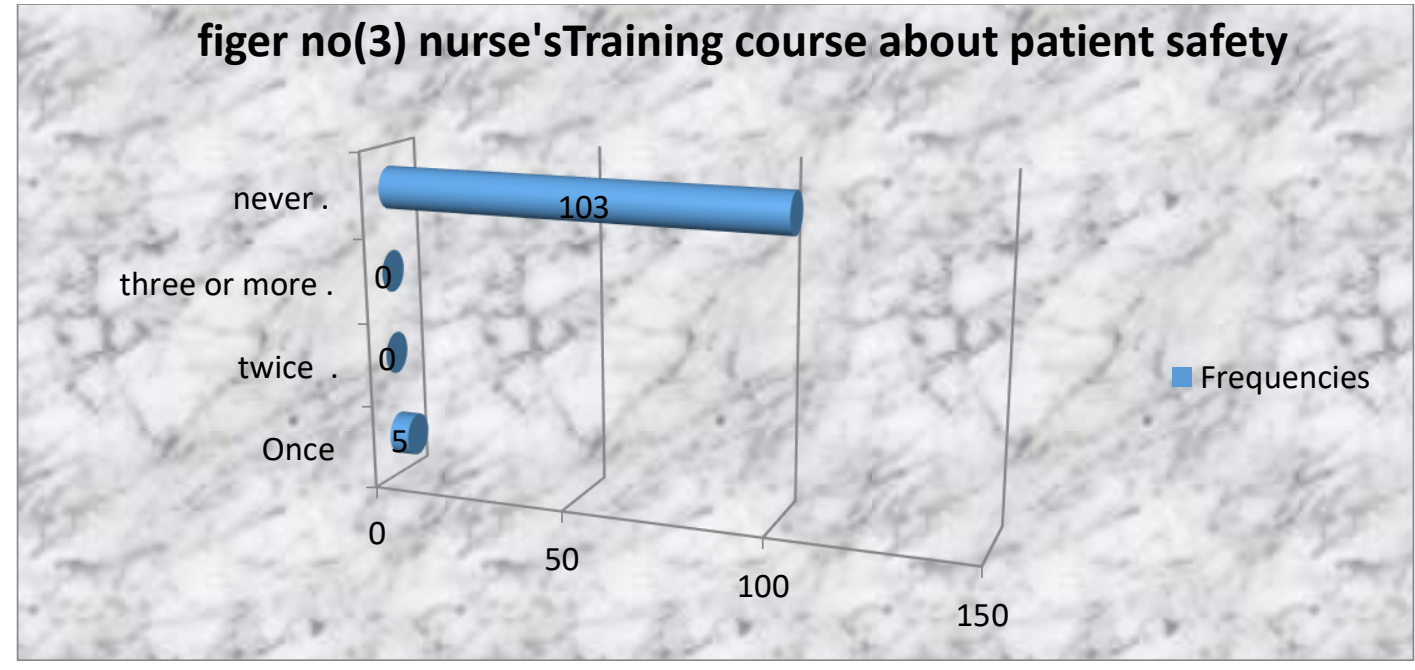

Table (1) represent comparison of the nurse's knowledge between pre and post test (I)

\begin{tabular}{|l|l|l|l|l|l|l|l|l|l|}
\hline \multicolumn{9}{|l|}{ Pre test } & \multicolumn{3}{l|}{ Post testI } & & & \\
\hline Mean & $\begin{array}{l}\text { Std. } \\
\text { Deviation }\end{array}$ & $\begin{array}{l}\text { Std. Error } \\
\text { Mean }\end{array}$ & Mean & $\begin{array}{l}\text { Std. } \\
\text { Deviation }\end{array}$ & $\begin{array}{l}\text { Std. Error } \\
\text { Mean }\end{array}$ & df & t & $\begin{array}{l}\text { Sig. (2- } \\
\text { tailed) }\end{array}$ \\
\hline 3.77 & 1.124 & .108 & 4.44 & .600 & .058 & 107 & 5.119 & .000 \\
\hline
\end{tabular}

Table (2) represent comparison of the nurse's knowledge between post test (I) and post test (II)

\begin{tabular}{|l|l|l|l|l|l|l|l|l|l|}
\hline \multicolumn{2}{|l|}{ Post test I } & \multicolumn{2}{l|}{ Post test II } & & & \\
\hline Mean & $\begin{array}{l}\text { Std. } \\
\text { Deviation }\end{array}$ & $\begin{array}{l}\text { Std. Error } \\
\text { Mean }\end{array}$ & Mean & $\begin{array}{l}\text { Std. } \\
\text { Deviation }\end{array}$ & $\begin{array}{l}\text { Std. Error } \\
\text { Mean }\end{array}$ & df & $\mathrm{t}$ & $\begin{array}{l}\text { Sig. (2- } \\
\text { tailed) }\end{array}$ \\
\hline 4.44 & .600 & .058 & 4.935 & .283 & .027 & 107 & 10.34 & .000 \\
\hline
\end{tabular}

Table (3) represent comparison of the nurse's knowledge between post test (II) and post (III)

\begin{tabular}{|l|l|l|l|l|l|l|l|l|l|}
\hline \multicolumn{2}{|l|}{ Post test II } & \multicolumn{2}{l|}{ Post test III } & & & \multicolumn{2}{|l|}{ (2- } \\
\hline Mean & $\begin{array}{l}\text { Std. } \\
\text { Deviation }\end{array}$ & $\begin{array}{l}\text { Std. Error } \\
\text { Mean }\end{array}$ & Mean & $\begin{array}{l}\text { Std. } \\
\text { Deviation }\end{array}$ & $\begin{array}{l}\text { Std. Error } \\
\text { Mean }\end{array}$ & df & $\mathrm{t}$ & $\begin{array}{l}\text { Sig. } \\
\text { tailed) }\end{array}$ \\
\hline 4.935 & .283 & .283 & 4.130 & .613 & .059 & 107 & 12 & .000 \\
\hline
\end{tabular}

Table (4) represent comparison of the nurse's knowledge between pre test and post (IV)

\begin{tabular}{|l|l|l|l|l|l|l|l|l|l|}
\hline \multicolumn{3}{|l|}{ Pre test } & Post test IV & & \\
\hline Mean & $\begin{array}{l}\text { Std. } \\
\text { Deviation }\end{array}$ & $\begin{array}{l}\text { Std. Error } \\
\text { Mean }\end{array}$ & Mean & $\begin{array}{l}\text { Std. } \\
\text { Deviation }\end{array}$ & $\begin{array}{l}\text { Std. Error } \\
\text { Mean }\end{array}$ & df & t & $\begin{array}{l}\text { Sig. } \\
\text { tailed) }\end{array}$ \\
\hline 3.76 & 1.124 & 0.108 & 4.129 & .613 & .059 & 107 & 2.96 & .000 \\
\hline
\end{tabular}

\section{Discussion}

The study reveal that (103 nurses ) most of them are younger, and most of them having nursing diploma (73) , (33) having baccalaureate and (2) having master degree , also most of them less experiences in their work area, (34) have experience less than one year , (49) (1-3 years ), (14) (36 years ) and only (11) have an experience more than (6years ), (103) they not received any training course about patient safety, only (5) nurses from the total (108 nurses ) have once training course. 
These findings indicated that study group were younger, have good level of knowledge but they were not expertise at their work site or have and training course which reflect on their care and present patient to risk.

Moreover, only less than one third of the nurses have very good level of knowledge concerning the general concept of patient safety, safety communication, safety medication administration, $(30 \%),(31 \%),(38 \%)$ respectively, pre application of the program but their knowledge was increase after implementation of the program post test one (86\%), (67\%), (70\%), post test two (84\%), (83\%), (96\%) and post test three (81\%), (83\%), (78\%) in addition to that, also less than half of them have very good level of knowledge pre program phase concerning infection control measures was (46\%), this result was improved to the best level in test one (94\%), post test two $(94 \%)$ and post test three $(88 \%)$ these finding indicated that nurses were not perform or follow infection control guidelines which present both of themselves and patients to harm.

The study results support other research findings indicating that, minimizing infection through improved infection Control as the study done to compromised the infection control in the developing countries with united states and the results conclude that:

According to the poor knowledge of the nurses working hospital between 5\% and $10 \%$ of patients admitted to modern hospitals in the developed world acquire one or more infections. - The risk of health care-associated infection in developing countries is from 2 to 20 times higher than in developed countries. In some developing countries, the proportion of patients affected by a health care-acquired infection can exceed 25\%. In the United States, 1 out of every 136hospital patients becomes seriously ill as a result of acquiring an infection in hospital; this is equivalent to two million cases and about 80000 deaths a year. ${ }^{(18)}$ Furthermore, it was clarified that nurses were promote patient monitoring and observation in a good manner pre program because less than two third of them (63\%), this result was improved after the application of the program; in post test one (70\%), post test two (92\%\%)and post test three $(77 \%)$ also the study justify that, there was highly statistical significant relationship between pre test and post test one, post test one and post test two, post test two and post test three $(\mathrm{p}=0.000)$, theses finding indicated the efficiency of the program in change the level of knowledge, if applied in proper way and it reflect on nurses quality of care and patient outcome.

The study results support other research findings indicating that, positive practice environment enhance patient safety outcome. As study done to explore the relationship between ward environment in which nurses practice and specific patient safety outcomes, the outcome were nurse reported patient safety level in ward in which they work, a quantitative cross sectional study was carried out, (108)general medical surgical nurse in 30 hospitals throughout Ireland, the result conclude that, the importance of ward level nurse factors such as educational level and work environment should be recognized and manipulated as important influence on patient safety ${ }^{(17)}$.

Another study was done to design training intervention and then test its effect on nurse leaders perception of patient safety, three hundred and fifty six nurses in clinical leadership roles in two Canadian multi site teaching hospitals (study and control), the result conclude that, Sensitively delivered training initiatives for nurse leaders can help to foster a safety culture. Organizational leadership support for improvement is, however, also critical for fostering a culture of safety. 
Together, training interventions and leadership support may have the most significant impact on patient safety culture ${ }^{(16)}$.

\section{Conclusion}

1) The mean of nurse's knowledge regarding maintain patient safety was improved, in pre intervention $(3.77+/-$ Std 1.24$)$ to be $(4.44+/-$ Std 0.60$)$ in post test I which get better to $(4.93+/-$ Std 0.283$)$ in post test II, and it was $(4.13+/-$ Std 0.613$)$ in post test III

2) There was statistically highly significant association between the nurses knowledge and application of training program.

3) Lack of training was stand as problem or barrier that preventing providing of good patient safety guide lines among nurses.

\section{Recommendations}

1) Continuous training courses about the patient's safety should be implemented for nurses

2) Application the patient's safety course in the nursing student curriculum.

3) Enhance the health care workers to perform the Essential Safety Requirement (ESR) in their working area.

4) Collaboration between institutions and federal ministry of health to Perform annual patient's safety conference and workshop and formalize a protocol with chick list as a tool that help ensure consistent application of key elements of evidence - based practice in patient safety.

\section{Reference}

[1] Mary Ann Friesen, Ronda G. Hughes, The Nurse's Role in Promoting a Culture of Patient Safety (2013), center of American nurse

[2] Chapman, Kimberly B. (2009, November). Improving Communication among Nurses, Patients, and Physicians. American Journal of Nursing, 109(11), 21-25. Available in website: http://journals.lww.com/ajnonline/Fulltext/2009/11001/Improving_Communication_Among_Nur ses,_Patients,.6.aspx

[3] Ronda G. Hughes, Rockville, MD 20850 AHRQ Publication No. 08-0043, April 2008, Patient Safety and Quality: An Evidence-Based Handbook for Nurses

[4] Vincent JL (November 2009) Improving Patient Safety, Intensive Care Med 26: S3-S8

[5] Sarah C Blake, Susan S Kohler, Steven D Culler, Jonathan Hawley, Kimberly J Rask Rollins School of Public Health, Emory University, USA Designing effective healthcare quality improvement training programs: Perceptions of nursing and other senior leaders, Journal of Nursing Education and Practice, 2013, Vol. 3

[6] Thomas R. Waters, Safe Patient Handling Training for Schools of Nursing DHHS (NIOSH) Publication No. 2009-127.

[7] Daryl A. Katz, Excellence in Nursing. Passion for Patient Care, Gerald P. Turner Department of Nursing Annual Report 2010-2011

[8] Pascale Carayon, Ayse P. Gurses, Nursing Workload and Patient Safety-A Human Factors, Patient Safety and Quality: An Evidence-Based Handbook for Nurses 2012.

[9] Michelle O'Daniel, Alan H. Rosenstein, Professional Communication and Team Collaboration, Patient Safety and Quality: An Evidence-Based Handbook for Nurses 2010. 
[10] Sean P. Clarke, Nancy E. Donaldson, Nurse Staffing and Patient Care Quality and Safety, Patient Safety and Quality: An Evidence-Based Handbook for Nurses: Vol. 2, 2014

[11] Carol Fowler Durham, Kathryn R. Alden, Enhancing Patient Safety in Nursing Education Through Patient Simulation, Patient Safety and Quality: An Evidence-Based Handbook for Nurses, 2015

[12] Angel, B. F., Duffey, M. \&Belyea, M. Clinical Instruction in Prelicensure Nursing Programs, National Council of State Boards of Nursing (NCSBN) Position Paper August 2005.

[13] Ronda G. Hughes, Tools and Strategies for Quality Improvement and Patient Safety, Patient Safety and Quality: An Evidence-Based Handbook for Nurses: Vol. 3,2015

[14] Group of World Health Organization (WHO), Better knowledge for safer care, Human Factors in Patent Safety 2009, WHO/IER/PSP/2009.05

[15] Stuart Emslie, Kirstine Knox and Martin Pickstone, improving patient safety insights from American, Australian and British health care, united kingdom / department of health.

[16] Kathleen Van Allen, safe staffing for pediatric patients, Chairperson, SPN Public Policy Committee society of pediatric nursing 2010.

[17] MarciaKirwan. AnneMatthews.P. AnneScott. The impact of the work environment of nurses on patient safety outcomes: A multi-level modelling approach. International Journal of Nursing Studies. Volume 50, Issue 2, February 2013, Pages 253-263

[18] LianeGinsburg,Close author notes See additional note Peter G. Norton,(e t a 1 ). An Educational Intervention to Enhance Nurse Leaders' Perceptions of Patient Safety Culture. Health Services Research. August 2005. Volume 40, Issue 4. Pages ix-x, 953-1258.

[19] Pratt RJ et al. Epic 2: National evidence-based guidelines for preventing health care-associated infections in NHS hospitals in England. Journal of Hospital Infection, 2007, 65S:S1-S64

\footnotetext{
*Corresponding author.

E-mail address: higazi124@yahoo.com
} 